\title{
Willingness to Communicate in L2: Persons' Emerging Capacity to Participate in Acts of Meaning Making with One Another
}

\author{
Magdalena Kubanyiova, School of Education, University of Leeds, UK \\ Zhen Yue, School of Foreign Studies, Xi'an Jiaotong University, China
}

\begin{abstract}
This study advances research into individuals' willingness to communicate in an additional language (L2 WTC) in classroom settings by departing from existing inquiry in two ways. First, it takes a multidimensional view of an "individual" in the classroom by integrating students' various identities as persons engaged in meaning making with others across different social worlds and over time. Second, it broadens the epistemological scope of current research by situating the study of WTC in students' actual acts of L2 communication in the classroom and in their larger sociocultural settings. Adopting broad principles of grounded theory ethnography, this study examined Jenny (pseudonym), a university student who was attending a general English course at her institution in mainland China. Data came from ethnographic classroom observations and life-story and photo-based interviews. The findings offer a refashioned definition of what it means to be willing to communicate in an L2 and how such willingness shapes the quality of one's investment in acts of L2 meaning making and L2 learning in communal relationships with others.
\end{abstract}

Keywords: L2 willingness to communicate (L2 WTC), willingness to participate (WTP), L2 learning, classroom discourse, grounded theory ethnography

Students' participation in L2 interaction has been theorized across diverse perspectives of SLA as critical to their L2 development in instructional settings (Kayi-Aydar, 2014; Mackey, 2007). Because students' willingness to take part has been assumed to be a crucial antecedent to such participation, the construct has become a focus of inquiry in its own right in SLA research under the umbrellas of willingness to communicate in L2 (L2 WTC; MacIntyre, Clément, Dörnyei, \& Noels, 1998) and, more recently, willingness to 
participate (WTP; Sert, 2015). This study is located at the intersection of these distinctive lines of inquiry.

The development of language learners' capacity to use L2 in meaningful communication has been a well-documented concern of language teachers, curriculum designers, and academic scholars. For example, in China, a number of L2 education policy initiatives have been proposed to address what some have seen as limited success in facilitating the development of students' L2 communication skills, often due to students' lack of WTC (Hu, 2002; Zhao, 2012; Zhou, 2015). This study contributes to L2 WTC theory building in the context of a specific L2 curricular effort at one of the top ten Chinese higher education institutions. Its curricular objective was to strengthen the focus on communication and increase students' willingness to participate actively in it. The data come from a larger project (Yue, 2014, 2016), whose objective was to take a deeper and sustained look at what actually transpires when these postgraduate students engage in L2 communication, to what extent and in what ways their "willingness" plays a role in the quality of this communication, and what may shape such willingness. In this article, we address these questions by focusing on one of the focal participants, Jenny (pseudonym), and examine her data from ethnographic classroom observations and post-observation conversations, photo-based interviews, and a life story narrative interview.

Originally framed as an L2 WTC study, the research reported here calls for extending the current theoretical and epistemological lens through which the study of individuals' "readiness to enter into discourse at a particular time with a specific person or persons, using a L2" (MacIntyre et al., 1998, p. 547) has typically been viewed. It does so by adopting the social underpinnings inherent in WTP approaches, which locate the study of individuals' willingness to communicate in the actual interactional setting rather than in the realm of hypothetically-oriented data, as much of existing WTC L2 research has tended to do. Our approach concurs with the WTP line of inquiry in the assumption that students' publicly observed engagement in classroom participation frameworks through discursive and embodied displays of, for instance, attentiveness, turn-taking, and taking on relevant participant roles (e.g., Evnitskaya \& Berger, 2017), can be understood as (potential) indexes of their willingness to engage. Turning to the study of such indexes as they evolve in the actual acts of communication represents a genuine opportunity for L2 WTC research. It allows linking the study of L2 WTC to contexts in which people are actually rather than hypothetically invested. It also allows studying contexts in which people's willingness (or 
lack thereof) is consequential to their meaningful participation in L2 meaning making and, by extension, in L2 learning (Kasper, 2004).

In contrast with the WTP strand's exclusive reliance on the micro-analysis of talk informed by ethnomethodology and conversation analysis (EMCA), our study adopts a broader grounded theory ethnographic approach (Kubanyiova, 2015). We are interested in how people use language for meaning making across different social worlds. Our study also affirms the value of "talk-extrinsic data" (Waring, Creider, Tarpey, \& Black, 2012), that is, data which shed further light on the sociocultural, ideological-normative, and biographical layers of talk. We maintain that these layers are embedded in and give meaning to individuals' here-and-now acts of communication, but may not always be easily discernible from public displays. The findings open up a renewed agenda for both future research and language pedagogy.

\section{Current Orientations to Research on Willingness to Engage in L2 Interaction} Willingness to Communicate (WTC)

WTC originated from Burgoon's (1976) concept of unwillingness to communicate which concerned individual differences in people's use of their mother tongue. It was conceived as a personality trait and regarded as fairly stable over time and across contexts. Accordingly, WTC was initially defined as a trait-like predisposition to initiate or avoid communication with others when the individual is free to do so (McCroskey \& Richmond, 1987). Subsequent research in applied linguistics, however, led to the recognition that WTC in L2 cannot be explained as a mere manifestation of L1 WTC. Instead, MacIntyre et al. (1998) went on to propose the now oft-cited multilayered "pyramid model" of L2 WTC, which features a range of linguistic, communicative, and social psychological variables that are thought to affect individuals' L2 WTC and, ultimately, their L2 use. In addition to specific trait dispositions, this model highlighted the state-dimension of the construct: One's WTC depends on one's willingness to initiate communication in a particular situation with a particular interlocutor. The subsequent empirical research in relation to this construct has never looked back.

For example, a greater consideration of the situated nature of L2 WTC has led to the recognition of the role of local sociocultural variables in affecting the individual's decision to approach or avoid communication in L2 (D’Amico, 2012; MacIntyre, Baker, Clément, \& Conrod, 2001; Peng, 2014). Taking a more fine-grained approach to context, Cao and Philp (2006) studied learners' levels of WTC in relation to three different classroom arrangements: 
pair work, group work, and whole class, concluding that each of these micro-settings affect individuals' WTC differently. As a result of this context-sensitive line of investigation, some have talked of L2 WTC as a state of flux (e.g., Pawlak \& Mystkowska-Wiertelak, 2015), while others have begun to look more closely at students' actual interaction in the classroom. For example, Yashima, MacIntyre, and Ikeda (2018) measured the amount of talk as well as silence between students' self-selected turns in classroom discourse, and used the resulting talk-silence ratio at the group level as an insight into the interaction between the so-called state and trait variables that contribute to individuals' L2 WTC.

To capture the various dimensions of an individual, WTC has drawn on research from across research on individual differences in SLA, such as self-concept, communication apprehension, or, more recently, future L2 selves (cf. Ghanizadeh, Eishabadi, \& Rostami, 2015; Peng, 2016; Yashima, 2009). In line with the cognitivist underpinnings of their sister domains in psychology, L2 WTC research has integrated these individual dimensions as more or less pre-defined and essentially measurable individual characteristics, albeit with the acknowledgment of their dynamic and situated nature (Dörnyei \& Ryan, 2015). A slower pace in identifying empirical consequences of this acknowledgement, however, has meant limited progress in understanding the different layers of the "person-in-context" (Ushioda, 2009) which would go beyond abstract categories and partial identities, such as EFL learners, Japanese students, and the like. Much less visible (for exceptions, see, e.g., Nikoletou, 2017) remains research that endeavours to study WTC by conceptualising individuals as persons whose biographies, identity projects and desires for meaning making with others collide with the broader socio-cultural and historical settings as they participate in specific acts of L2 communication.

\section{Willingness to Participate (WTP)}

The rise in context-conscious orientation to the study of L2 WTC represents a welcome and much needed shift. Yet, in its operationalization of context, much of L2 WTC work has remained focused on classifying different types of context along a priori categories and treating them as variables (e.g., cultural settings, learning environments, instructional conditions, or interactional moves) against which WTC has been measured. Less is known, however, about how the discursive circumstances give rise to individuals' desire to engage in meaning making with others. In other words, the primarily cognitivist orientation to L2 WTC has thus far allowed limited insights into what people are trying to accomplish as they engage 
in acts of L2 communication with one another across various meaning making events, and in what way (if at all) WTC figures in such acts.

It is against the backdrop of this limitation that a recent research direction has begun to evolve (cf. Sert, 2015). Pursued as a counter-argument to current L2 WTC research, part of this work has focused on understanding students' unwillingness to participate (UTP) in classroom discourse by adopting the analytical tools of EMCA (e.g., Eskildsen \& Majlesi, 2018) with the capacity to make visible individuals' investment in communication. In the case of WTP, for instance, an EMCA-informed study of observable indicators, such as withdrawals of mutual gaze or gaze aversions, long silences, minimal contributions or private turns can lead to insights into students' unwillingness to take part in classroom discourse and hence, to implications for potentially useful pedagogical interventions.

Our study suggests that an even more encompassing view of context has a role to play in deepening both WTC and WTP lines of inquiry and shedding light on immediate acts of participation and on the broader structural, ideological, social, psychological or moral planes in which the micro-moments of participation are embedded. We argue that while the principles of EMCA adopted in WTP line of inquiry place the study of willingness or otherwise in the immediate context of interactional action, they do not go far enough in embedding them in their wider ecological milieu. Our study shines a light on some aspects of this milieu, resulting in significant new insights as to what shapes people's desire to participate in acts of L2 communication with others.

\section{The Study}

\section{The research context and the research participant}

This study focuses on one of the focal participants in the larger study (Yue, 2014, 2016) studying general English (L2) at one of the top ten universities in China. Over the last few years, this university, like other higher education institutions in China, has made a series of reforms in EFL teaching to enhance students' communication skills (Zhao, 2012). One of these concerns offering students of non-English disciplines, an unattached listening and speaking course combined with a college English course in academic reading and writing. At postgraduate level, the university offers general English classes (e.g., International Communication, referred to as Class A from now on) typically taught by local teachers and foreign English classes (e.g., Listening and Speaking, Class B) taught by international teachers, with a weekly allocation of three and two hours respectively. The enrolment is 
achievement-based and is intended to have a motivational effect on students' English learning; those who perform well can transfer from the lower-level Class B to the higherlevel Class A whose lectures are more demanding and follow a faster pace.

Jenny was recruited in a purposive sample of several participants in the larger study and had no prior relationship with the researchers. There is no particular reason for choosing Jenny as the focus of the current study and the data of other participants could have been used equally effectively to illustrate its key findings. We decided to focus on one rather than more participants to allow, within the space constraints of a journal article, a more contextualised approach to understanding participants' interactions and the broader circumstances that had shaped those interactions.

Jenny was a 24-year-old first-year postgraduate student majoring in Law. She was assigned to Class A at the time of the study based on her English placement test results. She received informal English education through reciting without understanding the meaning from her father when she was three years old, and gradually became interested and confident in English thanks to her mother's encouragement to participate in English interest class in primary school. In middle and high schools, working as English representative in the class, she developed a good relationship with her English teachers, and actively participated in English communication activities, such as English speech contests. Jenny perceived her current English learning as more challenging especially in terms of using English in academic study. She was planning to take an IELTS test in the near future and prepare for study abroad. This project addresses broader research questions in relation to her L2 WTC, namely: what transpires when Jenny engages in L2 communication, to what extent and in what way does her willingness play a role in the quality of this communication, and what may shape such willingness?

\section{Data collection: Grounded theory ethnography}

Data collection and analysis were guided by grounded theory ethnography in order to advance a theoretical understanding of L2 WTC. We pursued grounded theory's emphasis on theory development (Strauss \& Corbin, 1994), that is, on understanding "plausible relationships" (p. 274) and "patterns of action and interaction between and among various types of social units (i.e., 'actors')" (p. 278). At the same time, we were committed to an ethnographic orientation and focused on Jenny's practice of meaning making across her social worlds. We paid attention to the types of L2 communication situations that Jenny experienced and endeavoured to understand what we could learn about her L2 WTC. This 
approach attempts to see the studied phenomenon from the participants' perspectives, while acknowledging that the theoretical consolidation will inevitably be a product of coconstruction of the researcher's and participants' interpretations (Charmaz \& Mitchell, 2001).

The second author was responsible for data collection, which was carried out over a period of one academic semester (14 weeks) at the previously described setting and included: (1) life story interviews, (2) ethnographic classroom observations, which included audiorecordings, fieldnotes and transcripts of classroom interactions, (3) post observation interviews, and 4) photo-based interviews (see Table 1 for full details).

Table 1 Summary of Data Collected from Jenny

\begin{tabular}{|c|c|c|}
\hline Data Sources & Number of entries & Total Length \\
\hline Life story interview (LSI)* & 2 & 1h 40mins \\
\hline Ethnographic classroom observation & 4 & $12 \mathrm{~h} 15 \mathrm{mins}$ \\
\hline Post observation interview (POI)* & 2 & 1h 05 mins \\
\hline Photo-based interviews (PBI)* & 5 & $3 \mathrm{~h} 35 \mathrm{mins}$ \\
\hline
\end{tabular}

Ethical clearance was granted by the authors' UK institution at the time of the larger study with full informed consent obtained from all participants prior to commencing research. Initially, in-depth life story interviews were conducted to get a sense of Jenny's understandings of her past and present language learning experiences and her future hopes. Audiorecordings and detailed field notes were produced for four three-hour lessons of Class A to gain insights into Jenny's observable behaviours in her actual classroom interactions. These were followed by post observation interviews to examine further interactional episodes potentially indexing her WTC. Throughout the study, Jenny also produced photos capturing what she evaluated as moments of meaningful L2 interactions outside of the classroom. She reflected on her choices in photo-based interviews.

We began our joint analysis by previewing transcripts of all data sources and outcomes of open coding conducted by the second author, which included a broad suite of themes also identified in existing WTC literature, such as parental investment, social 
relationships, language learning beliefs, and many others (for more detail on this process, see Yue, 2016). We shared the NVivo 10 file in which all data records and coding were stored, which allowed joint reading and re-reading of data records and an exchange of analytical memos on significant patterns that appeared across data sets. Specifically, we began to notice Jenny's frequent participation in the classroom as well as in her extracurricular activities, but at the same time, observed a distinctly different quality of this participation. On further interrogation of this phenomenon across Jenny's data, we identified a working theme of "fake vs. real WTC" and subjected all associated data to detailed scrutiny.

This led us to the WTP literature and to borrowing some of its analytical tools of examining classroom discourse for indexes of Jenny's WTC. We conducted a detailed analysis of Jenny's interactions with the teacher, paying particular attention to how each turn was produced and oriented to by the discourse participants and what, if anything, such participation patterns could tell us about Jenny's WTC. We further examined relevant talkextrinsic data, including Jenny's post-hoc accounts of those interactional moments in the discourse, all of which enabled us to account analytically for our initial insight of fake vs. real WTC and resulted in the narrowing down of our research questions and subsequent interrogation of Jenny's data concerning her extracurricular experiences. We utilised NVivo tools of memoing, annotating and "see also" links to cross-reference our emerging insights with the relevant data records and coding and to link these to existing literature in WTC, WTP and applied linguistics research more broadly. Through this joint process of analytical reflection, we arrived at our final theoretical consolidation. We make the interrogative process as well as the outcomes of this analytical approach transparent in our discussion of findings.

\section{Findings}

Jenny's willingness to participate as a perceived obligation to play by the rules: "I had to do $i t^{\prime \prime}$

We begin by examining one episode in Jenny's classroom observation data which signals her participation, private as well as public, in teacher-led discourse. In this class, the teacher was teaching academic letter writing by explaining formats, conventions and registers of different types of letter. The students were then required to translate a letter of refusal to demonstrate their ability to use the relevant language knowledge. The extract below focuses on Jenny and captures her involvement in this whole-class activity (for transcription conventions, see the Appendix). 


\section{L2 Classroom Interaction Excerpt (28 March 2012)}

(1) Teacher: ((to the whole class)) If you don't have difficulty, I hope you could translate for me, here (50) ((waits for students to read and think about the letter)) It is almost the same, right? Yeah, let's just try to remember immediately. How do we say? The first sentence?

(2) Jenny: ((talks to herself in a low voice)) Thank you for your letter.

(3) Teacher: ((to the whole class)) Yeah, thank you for your letter (.) ninth of (.)

(4) Jenny: ((talks to herself in a low voice)) nine of October two thousand and nine

(5) Teacher: ((to Jenny)) Yeah, you please. Let's do one by one, you do the first one.

(6) Jenny: Er. Thank you for your letter of nine of October two thousand and nine

(7) Teacher: $\{$ Uh-huh $=\}$

(8) S: $\quad$ inviting me to attend ((talking in the low voice) $)$ \}

(9) Jenny: =inviting me to attend the first international conference on the telemedical information society to be held in Amsterdam Netherlands (1) $\operatorname{Er}$ (1)

(10) Teacher: Yes, er, (1) yes, where do you put this 邀请我/yao qing wo/inviting me/ (2) Yes?

(11) Jenny: and inviting me.

(12) Teacher: Uh-huh, alright. ((to the whole class)) Any others still remember? Where did the author put this 并邀请我主持会议/bing yao qing wo zhu chi hui yi/and inviting me to host the conference/ (2) Where? Who still remembers? (2) Where did he put it? Pardon?

(13) SS: attend and chair.

(14) Teacher: Yeah, attend and chair, so that's enough. So thanks for your letter, and then inviting me to (1) attend and chair what? a session? of what?

Although the transcript may give the impression that the interaction concerns the teacher and Jenny as the only participants in this exchange, this is not an accurate portrayal of the participation patterns in Class A generally and in this transcript specifically. In fact, several students displayed participation patterns similar to Jenny's, in the private rather than public realm of classroom interaction, even though our focus means that the transcript foregrounds Jenny's discursive behaviour. Until turn 5, the teacher responded to these simultaneous private contributions from the class. Thus, although turn 3 appears to function 
as the teacher's public acknowledgment of Jenny's private contribution, it appears to have been a more general reaction to the sum of multiple private contributions (similar to turn 14), before inviting Jenny to participate in the public domain of teacher-led discourse. It is also worth mentioning that while the public exchange between Jenny and the teacher (turns 5-12) goes on, other students continue to interact privately, just like Jenny did in turns 2 and 4 in this transcript.

This clarification, made possible through our ethnographic data, matters for it shows the prevalent interactional culture in this classroom which is consequential to our findings and to which we return later. It is already clear, for instance, that students engage, but that self-selection, a discursive move typically treated as an index of willingness in both WTC (Yashima et al., 2018) and WTP literatures (Evnitskaya \& Berger, 2017), is clearly not supported by the existing interactional architecture of this classroom. To develop our analytical thread and study the significance of this insight in relation to Jenny's L2 WTC, however, let us turn our attention back to her.

This excerpt shows that when the teacher asked students to translate the first sentence of the letter, Jenny readily complied and engaged, albeit privately. At face value, this on-task L2 speaking behaviour appears to index Jenny's L2 WTC and has in fact resulted in the actual participation in public discourse. Indeed, her fuller dataset shows that she frequently engaged with the teacher's utterances by offering relevant responses privately in a low yet clearly detectable voice. Such private engagement is akin to interaction patterns observed in classrooms in Japan (Ohta, 2001) or New Zealand (Batstone \& Philp, 2013), and has been thought to represent important opportunities for language learners to engage in mental rehearsal, private speech or collaborative dialogue, key features in the process of internalisation from, for example, the sociocultural perspective to SLA (Swain, Kinnear, \& Steinman, 2011). The empirical questions that arise are, first, does Jenny's visible, private and public, participation in teacher-led discourse index her WTC and second, does it matter either way? The following excerpt offers a relatively clear-cut answer to the first. It comes from a post-observation interview of the previous episode and suggests that Jenny's participation was linked to something other than WTC. As she notes,

I perceived the teacher's question as one for the whole class, and she didn't indicate any individual to answer it primarily, so I thought the teacher hoped for us to answer together. [...] In Chinese classrooms in higher education, most of the questions asked 
by the teacher are for the whole class, unless someone is appointed. Students can think about the questions in their heart or think aloud. (POI, 28 March 2012)

Jenny's account suggests that answering the teacher's questions in private is part of the broader interactional culture in this specific class, into which students, including Jenny, have been well socialised and which was clearly visible in the observational data of this study. Jenny did not orient to this type of classroom interaction as an opportunity for L2 communication and therefore as a context in which her WTC could be exercised. Instead, she seemed to treat it as an opportunity to accept the perceived invitation to "think aloud", that is, to display her attentiveness and thus make visible her compliance with established norms of classroom interaction in this setting. Although a surface analysis could well link Jenny's discursive behaviour to her willingness to participate, a closer inspection offers further insights into the nature of this participation: it is not so much her desire to communicate as it is her willingness to play by the rules that governs her private involvement in this interactional episode.

Jenny's subsequent reflection sheds further light on the nature of her public participation, suggesting that rather than a social display of her desire to contribute, it was in fact an unintended social consequence of its very opposite:

I had to do it when the teacher asked me to answer the question, but I was not sure about the answer, so I felt that I was forced to do it, otherwise, I will use eye contact to let the teacher know that I would like to do it, then she can call my name, but in that case, I didn't do that. (POI, 28 March 2012)

The data portray Jenny as someone who had developed a complex semiotic repertoire to signal her discursive intentions. Her on-task private contributions to the teacher's questions indexed her willingness to participate in the established interactional routines and sociocultural norms in Class A, but displayed her willingness to participate in public teacherled discourse only when accompanied by her "eye contact" with the teacher. By deliberately withholding her gaze in this interaction, Jenny intended to send an unambiguous signal of her unwillingness to shift her private participation to the public realm: she "was not sure about the answer" and therefore not prepared to take part in teacher-led discourse. The teacher's failure, be it unconscious or deliberate, to heed these semiotic clues left Jenny with no choice 
but to get involved publicly. She simply "had to" respond to the question to comply with established sociocultural norms of participation in this class.

It is possible that the desire to conform may well be an initial step towards successful communication in L2 and therefore an important layer of L2 WTC (although see Garton, 2012; Kubanyiova, 2015; Waring, 2009 for examples when speaking "out of turn" rather than conforming to existing discourse practices constituted more meaningful opportunities for students' L2 development in specific interactional settings). Similarly and equally reasonably, we may conclude that willingness to play by the rules is a necessary and sufficient condition for language learning if it is skilfully mobilized by the teacher, as occurred in this transcript. After all, Jenny's socially displayed willingness to play by the rules clearly resulted in her public participation which, though it may have felt "forced" to Jenny, was still meaningful within the interactional microcontext whose pedagogical objectives related to checking and displaying understanding of new linguistic knowledge (cf. Walsh, 2006).

Yet, however these findings are interpreted, they do not dispose of the empirical question whether willingness to play by the rules is identical with or related to the original conception of L2 WTC (or WTP for that matter) that has been seen as a prerequisite for L2 communication and on which the relevance of this domain of inquiry rests. We return, therefore, to the second question of our inquiry: In the face of objective evidence of Jenny's actual participation in public discourse, does it matter that it is, equally unambiguously, an unintended consequence of her unwillingness? To address it, we turn to Jenny's additional sets of data to understand what she does orient to as communication and what, if any, difference this makes to the quality of her engagement with L2 learning.

Jenny's participation as emerging capacity to transgress the rules of play: "they were all astonished and laughed about it"

The following communication scenario concerns Jenny's experience in the so-called "English Corner", an extra-curricular activity organized by her international teacher. The photo that Jenny provided as part of her data depicts an L2 conversation on the topic of April Fools' Day that she had together with another six participants, including: a non-Chinese English language teacher who organized the activities, an exchange student from the United States, and another four Chinese students. In the photo-based interview, Jenny referred to the image capturing the experience (see Figure 1) as "one of the most impressive moments" in her L2 communication. 


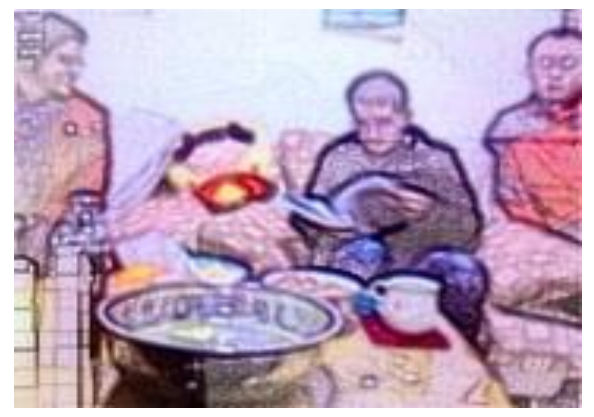

Figure 1. Jenny's Photo of a Communicative Activity Outside L2 Classroom (Images have been intentionally distorted to preserve anonymity)

Our foreign teacher told us that when she was in high school, she played tricks on her mum by telling her she got pregnant to celebrate the April Fools' Day. We were so surprised and amused by her story, and started to share our own funny and interesting experiences, without being shy anymore. At the beginning I felt embarrassed to talk about how you either tricked somebody or you were fooled by others, but later, I felt there was nothing embarrassing, so I shared how I tricked my teacher when I was in high school, and they were all astonished and laughed about it. At that moment, I was very excited, and I was speaking out directly without preparation, just like telling my own story. We were all excited and wanted to join in the interesting conversation, so the atmosphere was very active. (PBI, 27 March 2012).

As opposed to Jenny's willingness to abide by the default discursive norms of interaction in Class A, here we get a sense of her gradual awakening to the joys of transgressing them. This is, coincidentally but perhaps also consequentially, reflected in the very topic of Jenny's conversation: playing tricks on someone in a position of authority. Jenny's emerging transgression from the rules of play thus symbolically concerns both the sociocultural conventions regarding social conduct more generally (what was initially thought by her as socially embarrassing to do let alone disclose is no longer so) and the norms governing interaction for language learning purposes. Here the data give us a glimpse of her growing appreciation of how the language that she is learning can be harnessed communally to surprise, to amuse, to violate apparent social norms, to astonish, to generate laughter, to tell "my own story". In short, we witness Jenny's emerging capacity to participate in L2 meaning making with others. This is very different from her capacity to participate in classroom discourse practices in her Class $\mathrm{A}$ and is in fact predicated on transgressing the norms governing such practices. It could be argued, therefore, that Jenny's willingness to participate 
is now of a very different kind and concerns willingness to communicate in the fuller sense of the term. We posit that this shift in the quality of Jenny's participation from conforming to established discourse routines to meaning making signals the need to account for it in WTP and WTC theorizing and we will return to this point later in our discussion.

It also has to be stressed, however, that Jenny did not enter this outside of the classroom language learning environment with "excitement" but rather with initial reluctance out of fear of "embarrassment". Clearly, the teacher's sharing with the students played a crucial role in disrupting the discursive norms that Jenny was accustomed to and grew to expect in an English class. By transgressing the prevalent norms herself, the teacher loosened the grip on the rules of play and thus gave the legitimacy for students' acts to follow suit. Jenny's newfound willingness, therefore, is not something that she had and which was somehow activated by the different learning environment. Instead, her desire to communicate emerged in the actual act of meaning making with others.

Our findings concur with WTC research on the role of contributing "factors", in this case the teacher in particular (cf. Peng, 2014), but also advance understanding further. In our study, it was not the teacher as a variable with specific characteristics that made a difference to the quality of Jenny's participation. Rather, it was the teacher's own communication orientation within the specific conversation, that is, her own willingness to attend to the English Corner participants as persons with things to say to each other that made Jenny's transgression from the established classroom interactional patterns, and therefore, her participation in meaning making, possible. Our finding suggests that WTC might be best explained as persons', including the teacher's, emerging capacity to make meaning with one another.

Jenny's language learning in the context of her emerging capacity to participate in L2 meaning making with others: "it was more like a part of my life"

So far, our data have alerted us to crucial differences between Jenny's willingness to participate in established norms of classroom discourse and her willingness to communicate in the fuller sense of the word; that is, to make meaning with others. In doing so, we have disentangled threads in the tapestry of willingness, which problematize or at least further complexify current theorizing. Here we wish to delve deeper into the issue of what, if any, consequences the different types of willingness may have had for Jenny's language learning and what, if anything, this means for both the study of willingness in the broader domain of 
SLA and, even more pressingly, for the policy and practice of language education in institutional settings.

The next piece of data concerns a set of two photos (see Figure 2) that Jenny chose as representing one of the "happiest days" since she started attending the English Corner:
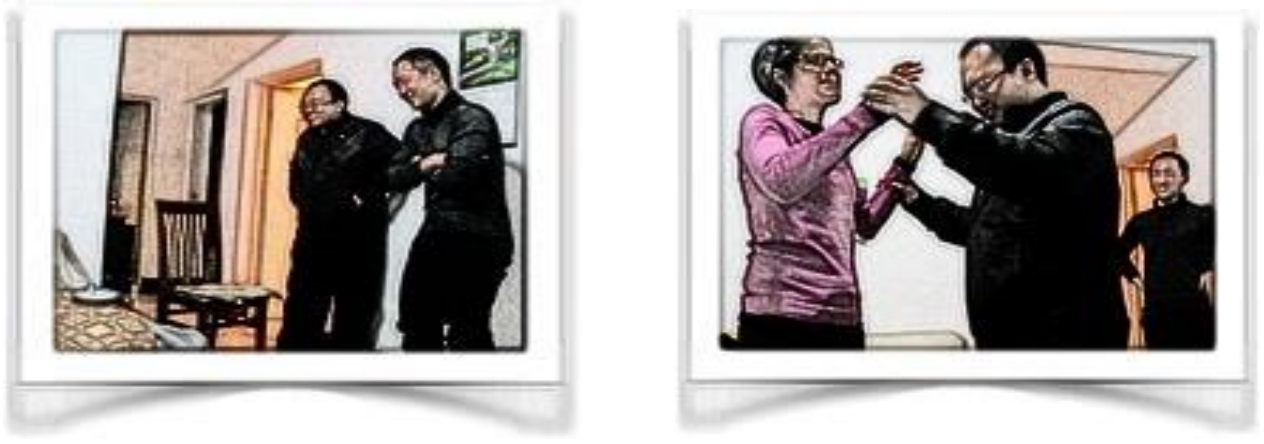

Figure 2. Communicative Activity in the English Corner Captured by Jenny

Everyone was high, especially when they were dancing, it was more like a part of my life, I mean at the beginning I went there with a purpose to practice and improve my speaking, but after this period, we got familiar with each other, the teacher and peers, they are nice, so it is more like friends getting together and having fun together, I think if I have time, I would go there every week. (PBI, 20 April 2012)

Establishing a positive social climate has been seen as a double-edged sword. On the one hand, positive teacher-student relationships are known to contribute to more engaging language learning experiences (e.g., Henry \& Thorsen, 2018) but, on the other, the social cohesiveness of the group that results from it may jeopardise the group's pursuit of academic goals (Dörnyei \& Murphey, 2003). Jenny's reflection may signal the threat of the latter, but a closer examination of her full dataset shows that the growing social bond with her fellow English Corner participants marks a significant transition in her investment in L2 learning with far reaching consequences for her WTC and for her future as an L2 user/communicator. The following two examples from Jenny's data illustrate this point.

In the first, Jenny describes her lunch with the English Corner participants, whom she has now begun to see "like friends". The communication episode that left an imprint on her memory concerned translating a restaurant menu and explaining ingredients for each course to two international teachers. This is how she recounted the event: 
Although I found it was a little bit difficult, it didn't affect my mood to enjoy the conversation, it was interesting and more like daily conversation between people, like friends get together, then eating and chatting. I remember one thing was funny that I was trying to explain the sow thistle cold and dressed with sauce, but I didn't know how to say sow thistle in English, so I used the word 'bitter' instead...the two teachers were so confused about what I said, so one boy tried to explain by saying that if you have a bad mood, you need to eat this, it tastes bitter, the important thing is that everyone could engage in our conversation and we really had fun. I also learned how to use the word 'acid', as when I explained the boiled fish with pickled cabbage and chili, I used the word 'acid', then our teacher pointed out that acid should be used in industry not in food. ... I mean although I made some mistakes, and my friends as well, we didn't worry too much about it, you would not feel you lost your face, while sometimes you felt you brought happiness to others. (PBI, 12 June 2012)

Even in the absence of data of the actual interactions that Jenny is referring to in her photo-based interviews, her desire to make meanings with others and her engagement with the new language is clearly visible in her meta-linguistic reflections on her lived experiences. The transcript shows Jenny's newfound willingness to take risks with language, to negotiate meaning and to overcome difficulties and anxieties in the service of meaningful communication. And even if we do not see any of this in situ, we do witness, here and across her outside-of-the-classroom data, clear evidence of Jenny's active here-and-now engagement with the newly encountered language. Whether this engagement is viewed across SLA paradigms as language use (Kasper, 2004), languaging (Swain et al., 2011), or linguistic uptake (Gass \& Mackey, 2006), Jenny's English Corner data show numerous examples of such active and concrete language learning practice in the context of her desire to make meaning with others. A complete lack of such detail from her Class A data clearly points to significant differences in the quality of Jenny's language learning and use across these two situations, suggesting a crucial connection between WTC, conceptualized as persons' emerging capacity to make meaning with others, and language learning.

Interestingly, Jenny makes every effort to channel her emerging desire to make meaning with others into contexts with similar instructional objectives to her Class A, such as IELTS preparation or English language competition. In the final example, Jenny talks about an English speech competition organized by her department, which she joined because it was 
“a valuable opportunity to practise L2 speaking”. Her original intention was to practise for the IELTS test. However, rather than choosing a straightforward topic that would guarantee her success, Jenny opted for a risky subject: a new buzzword on the internet, “loser”(帛丝 /diao si), in order to challenge people's conceptions of this word, typically taken by others in her wider social circle to mean something controversial, rough and generally negative and inappropriate. As she explained, "I wanted to challenge, I wanted to tell others, there will be different understandings of this word, not only how they interpreted it, but there are more positive interpretations attached to it” (PBI, 4 June 2012).

In sharp contrast with her participation in Class A, Jenny's engagement with language in this setting is eminently not from the position of someone willing to conform to the rules of play, even though doing so is inherently tied to the organizational structure of this setting. Instead, her willingness - desire and passion even - to share in the meaning making with others means that she is once again, but now even more resolutely and deliberately, willing to transgresses the rules of play and face potential social and academic repercussions of disrupting the established social order of institutional interaction.

In fact, many judges approached the speaking contest in the same way as the teacher in Class A. They expected contestants to conform to default discursive norms that would allow a judgement on how well this was achieved. As far as they were concerned, Jenny clearly failed in that task. In her words, they "laughed weirdly, frowned, shook their heads and sneered about what I said concerning my topic", made her feel "nervousness or even forgetting what I was going to say" and, crucially, ended up giving her "very low scores" (PBI, 4 June 2012). Fortunately for Jenny, however, there were also judges who were able and willing to suspend their expectations of default participation patterns and, prompted by her unexpected discursive behaviour, began to see Jenny as a communication partner. In other words, they came to shift their orientation to the event not simply as a space to observe and judge correct answers, but rather as an opportunity for communal meaning making. It is the latter group of judges who gave Jenny a "very high score" and in that way enabled her to proceed further in the competition. We venture to suggest that without these judges' own emerging WTC with Jenny, her desire to make meaning and, consequently, her deep investment in language learning, may have been short-lived, as her Class A data remind us. 


\section{Discussion and Conclusions}

\section{A theoretical challenge to the official L2 WTC canon}

The initial aim of this research was to understand Jenny's WTC across her L2 communication settings and our progressive immersion in her data guided our inquiry towards two specific questions: First, does Jenny's visible participation in classroom discourse index her willingness to communicate and second, does it matter either way? Locating the study of Jenny's willingness at the intersection of WTC and WTP lines of inquiry has compelled us to affirm communication as central to the study of willingness and, by extension, language learning.

Stating this, however, does not mean endorsing one strand of research over the other. On the contrary, the intricate threads in the patterns of Jenny's discursive behaviours across her social worlds of L2 meaning making with others have problematized the notion of communication as mere speaking that WTC research has tended to assume through its theorizing and prevalent research designs. Similarly, our study has shown that not all participation in discourse, which WTP line of inquiry has helped to make visible but has perhaps been less able to disentangle, is attributable to people's desire to make meaning with one another. Yet, our study has shown that it is only when such communal desire is embedded, enabled and nurtured within the given discursive structures that we can meaningfully link WTC/WTP with deep and sustained investment in language learning and thus make a more confident case for the domain's disciplinary relevance in the broader terrain of SLA and applied linguistics.

More specifically, our findings present a significant theoretical challenge to the official L2 WTC canon in their insistence on the central place of a reciprocal person-to-person communication in peoples' WTC. The data have shown WTC as emerging inside such communication, rather than as a characteristic that individuals pre-possess and that different communicative circumstances either facilitate or hinder. The distinction is crucial for it suggests that although this emerging, rather than pre-existing, capacity includes individuals' here-and-now "action control" (MacIntyre \& Doucette, 2010, p. 8), it also unmistakably signals the ineradicable and consequential role of the other persons' contribution to it. This, we argue, is an ontological as much as an epistemological insight, which alters not simply the way we research, but how we talk about the thing we research. Our refashioned definition of WTC as persons' emerging capacity to participate in acts of L2 meaning making with one another reflects this shift with a major theoretical, analytical and, ultimately, ethical 
consequence: WTC may not be easily accounted for as an individual difference, regardless of the number of factors that may be theorized to constitute and shape its complex and dynamic whole (cf. Dörnyei \& Ryan, 2015). Instead, because WTC essentially arises inside a particular human relationship rather than in an individual, the unit of analysis must be reoriented accordingly. The future research effort towards this re-orienting is as much a question of scientific rigour as it is one of responsible science (Geertz, 2000).

\section{Towards a third way of researching $L 2$ WTC}

Our research has shown that recent efforts to investigate individuals' willingness by adopting an epistemological orientation of the WTP paradigm have much to offer to the study of WTC conceptualized as persons' emerging capacity to participate in acts of L2 meaning making with one another. This broader EMCA perspective to SLA, as Kasper and Wagner (2018) remind us, pays attention to how objects of inquiry, which include WTC, are brought into being by the participants through their joint action. WTP line of inquiry, which is fully rooted in EMCA, is therefore aptly positioned to contribute to the challenging new agenda for WTC which places person-to-person communication at its centre.

We took inspiration from this line of inquiry and by so doing departed fundamentally from the prevalent cognitivist orientation of the traditional L2 WTC inquiry. At the same time, we readily acknowledge our study's limitations in generating the analytical detail that EMCA deems essential. It is quite likely, for instance, that taking an EMCA-informed finegrained and multimodal approach to collecting and analysing interactional data across Jenny's communication settings might have brought into a sharper relief some of the layers of findings that we were only able to unearth through our recourse to alternative sources of data, such as photo-based interviews. We fully endorse an analytical commitment to studying acts of communication both in the classroom and "in the wild" (Theodórsdóttir, 2018) as a particularly promising direction for future WTC inquiry. At the same time, however, focusing our analytical lens on action as EMCA does while using additional tools of grounded theory ethnography has allowed us not only to build on research advanced by WTP but also to surpass its analytical and theoretical reach.

The grounded theory ethnographic approach that we adopted for this study draws on its anthropological heritage in the conviction that researching people's communication and, by the same token, their desire to participate in it, involves "direct, intimate, and more or less disturbing encounters with the immediate details of contemporary life" (Geertz, 2000, p. 22). Inherent in this conviction is the recognition that this desire or willingness is "managed 
immediately and subtly through the normative resources of interaction” (Potter, 2012, p. 576). But this approach also acknowledges with humility that the meaning of that which is visible may not be readily obvious to the analyst without painstaking piecing together other pieces of the mosaic. Although this diverges somewhat from the philosophical underpinnings of EMCA (but see Waring et al., 2012), we see this "third way" of researching as contributing just as vigorously to the larger project of revisiting psychological concepts in research on language learning and teaching from the praxeological perspective (Kasper \& Wagner, 2018; Kubanyiova, 2019; Kubanyiova \& Feryok, 2015).

\section{Implications for managing communication in instructional settings}

Finally, the newly re-theorized WTC makes an appeal for classroom pedagogy that departs radically from typical calls for creating communicative environments through tasks, techniques or topics. In contrast with some of the principles of task-based language teaching (TBLT), for instance, our study shows that what students talk about seems to be of lesser than assumed consequence to their WTC and to their deep investment in language learning. What does matter is that they do so in the context in which the other person is ready to receive and reciprocate in the act of meaning making.

Jenny was perfectly comfortable solving linguistic puzzles and engaged in languaging with her new friends in the English Corner. But she did so not as a student who "had to" abide by the institutional rules of play but rather as a friend, a food lover or a multilingual expert user, who was willing to transgress default discursive norms in the service of communal meaning making. Richards (2006, quoting Zimmerman's (1998) framework of identity in discourse) has empirically linked these so-called "transportable identities" to the possibility of genuine conversation in the classroom, while Ushioda (2011) has extended this argument to motivational language teaching. Our findings concur but also cast further light on this relationship. They make it apparent that allowing students to "speak as themselves" (Ushioda, 2011) is a necessary but insufficient condition for nurturing their WTC.

Jenny showed through her engagement with language in the English competition that she was willing and ready to talk about a seemingly random vocabulary item as "herself", even despite the expectations to the contrary. We speculated, however, that her willingness could only ever thrive in the presence of someone willing and ready to receive her message, or, in her own words, to "be astonished" or "laugh about it". In a similar vein, creating opportunities for students to initiate speaking in their classroom, assumed by both WTC and WTP paradigms as the key index of their willingness, is only a half of the picture. The 
success of the other half depends on how the other, the classroom teacher in particular, acts on that initiation.

It must be acknowledged, however, that educators too depend for their capacity to make meaning with their students on the affordances in their wider social ecology. Jenny's teacher, after all, may never have experienced let alone been encouraged by her sociocultural and educational environment to orient to her instructional practices as potential acts of meaning making. Similarly, her experiences, as well as those of her students, may also have been guided by some unhelpful language ideologies impacting on their communal desire to make meaning with one another (Subtirelu, 2014). Curricular initiatives tasked with enhancing students' communication in the classroom may thus need to begin with a broader reflection on how language educators can be supported through language teacher education and wider cultural practices (cf. Kubanyiova, 2018).

\section{References}

Batstone, R., \& Philp, J. (2013). Classroom interaction and learning opportunities across time and space. In K. McDonough \& A. Mackey (Eds.), Second language interaction in diverse educational contexts (pp. 109-125). Philadelphia/Amsterdam: John Benjamins.

Burgoon, J. K. (1976). The unwillingness to communicate scale: development and validation. Communication Monographs, 43(1), 60-69. doi:10.1080/03637757609375916

Cao, Y., \& Philp, J. (2006). International context and willingness to communicate: a comparison of behavior in whole class, group and dyadic interaction. System, 4(4), 480-493. doi:10.1016/j.system.2006.05.002

Charmaz, K., \& Mitchell, R. G. (2001). Grounded theory in ethnography. In P. Atkinson, A. Coffey, S. Delamont, J. Lofland, \& L. Lofland (Eds.), Handbook of ethnography (pp. 160-174). Los Angeles, CA: Sage.

D'Amico, M. L. (2012). L2 fluency and willingness to communicate: the impact of shortterm study abroad versus at-home study. US-China Foreign Language, 10, 16081625.

Dörnyei, Z., \& Murphey, T. (2003). Group dynamics in the language classroom. Cambridge, MA: Cambridge University Press.

Dörnyei, Z., \& Ryan, S. (2015). The psychology of the language learner revisited. New York, NY: Routledge.

Eskildsen, S. W., \& Majlesi, A. R. (2018). Learnables and teachables in second language talk: Advancing a social reconceptualization of central SLA tenets. Introduction to the Special Issue. The Modern Language Journal, 102(SI), 3-10. doi:10.1111/modl.12462 
Evnitskaya, N., \& Berger, E. (2017). Learners' multimodal displays of willingness to participate in classroom interaction in the L2 and CLIL contexts. Classroom Discourse, 8(1), 71-94. doi:10.1080/19463014.2016.1272062

Garton, S. (2012). Speaking out of turn? Taking the initiative in teacher-fronted classroom interaction. Classroom Discourse, 3(1), 29-45. doi:10.1080/19463014.2012.666022

Gass, S., \& Mackey, A. (2006). Input, interaction and output: An overview. AILA Review, 19, 3-17. doi:10.1075/aila.19.03gas

Geertz, C. (2000). Available light: Anthropological reflections on philosophical topics. Princeton, NJ: Princeton University Press.

Ghanizadeh, A., Eishabadi, N., \& Rostami, S. (2015). Motivational dimension of WTC in L2: The impacts of ideal L2 self, family influence, and attitudes to L2 culture. International Journal of Research Studies in Education, 4(5), 13-24. doi:10.5861/ijrse.2015.1261

Henry, A., \& Thorsen, C. (2018). Teacher-student relationships and L2 motivation. The Modern Language Journal, 102(1), 218-241. doi:10.1111/modl.12446

$\mathrm{Hu}, \mathrm{G}$. (2002). Potential cultural resistance to pedagogical imports: The case of communicative language teaching in China. Language, Culture and Curriculum, 15(2), 93-105. doi:10.1080/07908310208666636

Kasper, G. (2004). Participant orientations in German conversation-for-learning. The Modern Language Journal, 88(4), 551-567. doi:10.1111/j.0026-7902.2004.t01-18-.x

Kasper, G., \& Wagner, J. (2018). Epistemological reorientations and L2 interactional settings: A postscript to the Special Issue. The Modern Language Journal, 102(SI), 82-90. doi:10.1111/modl.12463

Kayi-Aydar, H. (2014). Social positioning, participation, and second language learning: Talkative students in an academic ESL classroom. TESOL Quarterly, 48(4), 686-714. doi:10.1002/tesq.139

Kubanyiova, M. (2015). The role of teachers' future self guides in creating L2 development opportunities in teacher-led classroom discourse: Reclaiming the relevance of language teacher cognition. The Modern Language Journal, 99, 565-584.

Kubanyiova, M. (2018). Language teacher education in the age of ambiguity: Educating responsive meaning makers in the world. Language Teaching Research, Online First, 1-11. doi:10.1177/1362168818777533

Kubanyiova, M. (2019). A discursive approach to understanding the role of educators' possible selves in widening students' participation in classroom interaction: Language teachers' sense making as 'acts of imagination'. In H. Henderson, J. Stevenson, \& A.M. Bathmaker (Eds.), Possible selves and higher education (pp. 59-77). New York, NY: Routledge.

Kubanyiova, M., \& Feryok, A. (2015). Language teacher cognition in applied linguistics research: Revisiting the territory, redrawing the boundaries, reclaiming the relevance. The Modern Language Journal, 99(3), 435-449. doi:10.1111/modl.12239

McCroskey, J. C., \& Richmond, V. P. (1987). Willingness to communicate. In J. C. McCroskey \& J. A. Daly (Eds.), Personality and interpersonal communication (pp. 129-156). London, UK: Sage 
MacIntyre, P., Baker, S., Clément, R., \& Conrod, S. (2001). Willingness to communicate, social support, and language-learning orientations of immersion students. Studies in Second Language Acquision, 23(3), 369-388. doi:10.1017/s0272263101003035

MacIntyre, P. D., Clément, R., Dörnyei, Z., \& Noels, K. A. (1998). Conceptualizing willingness to communicate in a L2: A situational model of L2 confidence and affiliation. The Modern Language Journal, 82(4), 545-562. doi:10.1111/j.15404781.1998.tb05543.x

Mackey, A. (Ed.). (2007). Conversational interaction in second language acquisition. Oxford, UK: Oxford University Press.

Nikoletou, P. (2017). A 'person-in-context relational' approach to understanding students' willingness to communicate in an additional language in higher education in Greece: Only the tip of an iceberg ( $\mathrm{PhD}$ thesis). University of Birmingham, Birmingham, UK.

Ohta, A. S. (2001). Second language acquisition processes in the classroom: Learning Japanese. Mahwah, NJ: Lawrence Erlbaum.

Pawlak, M., \& Mystkowska-Wiertelak, A. (2015). Investigating the dynamic nature of L2 willingness to communicate. System, 50, 1-9. doi:10.1016/j.system.2015.02.001

Peng, J. E. (2014). Willingness to communicate in the Chinese EFL university classroom: an Ecological perspective. Bristol, UK: Multilingual Matters.

Peng, J. E. (2016). The context-sensitivity of self-concept and willingness to communicate in the Chinese EFL classroom. In J. King (Ed.), The dynamic interplay between context and language learner (pp. 84-103). Basingstoke, UK: Palgrave Macmillan.

Potter, J. (2012). How to study experience. Discourse and Society, 23(5), 576-588. doi:10.1177/0957926512455884

Richards, K. (2006). "Being the teacher": Identity and classroom conversation. Applied Linguistics, 27(1), 51-77. doi:10.1093/applin/ami041

Sert, O. (2015). Social interaction and L2 classroom discourse. Edinburgh, UK: Edinburgh University Press.

Strauss, A., \& Corbin, J. (1994). Grounded theory methodology. Handbook of Qualitative Research, 17, 273-285. doi:10.4324/9780203409527.ch13

Subtirelu, N. (2014). A language ideological perspective on willingness to communicate. System, 42, 120-132. doi:10.1016/j.system.2013.11.004

Swain, M., Kinnear, P., \& Steinman, L. (Eds.). (2011). Sociocultural theory in second language education: An introduction through narratives. Bristol, UK: Multilingual Matters.

Theodórsdóttĭr, G. (2018). L2 teaching in the wild: A closer look at correction and explanation practices in everyday L2 interaction. The Modern Language Journal, 102(SI), 30-45. doi:10.1111/modl.12457

Ushioda, E. (2009). A person-in-context relational view of emergent motivation, self and identity. In Z. Dörnyei \& E. Ushioda (Eds.), Motivation, language identity and the L2 self (pp. 215-228). Bristol, UK: Multilingual Matters.

Ushioda, E. (2011). Motivating learners to speak as themselves. In G. Murray, X. Gao, \& M. Lamb (Eds.), Identity, motivation and autonomy in language learning (pp. 14-33). Bristol, UK: Multilingual Matters. 
Walsh, S. (2006). Investigating classroom discourse. New York: Routledge.

Waring, H. Z. (2009). Moving out of IRF (Initiation-Response-Feedback): A single case analysis. Language Learning, 59(4), 796-824. doi:10.1111/j.1467-9922.2009.00526.x

Waring, H. Z., Creider, S., Tarpey, T., \& Black, R. (2012). A search for specificity in understanding CA and context. Discourse Studies, 14(4), 477-492. doi:10.1177/1461445611433787

Yashima, T. (2009). International posture and the ideal L2 self in the Japanese EFL context. In Z. Dörnyei \& E. Ushioda (Eds.), Motivation, language identity and the L2 self (pp. 144-192). Bristol, UK: Multilingual Matters.

Yashima, T., MacIntyre, P. D., \& Ikeda, M. (2018). Situated willingness to communicate in an L2: Interplay of individual characteristics and context. Language Teaching Research, 22(1), 115-137. doi:10.1177/1362168816657851

Yue, Z. 2014. Chinese university students' willingness to communicate in the L2 classroom: The complex and dynamic interplay of self-concept, future self-guides and the sociocultural context. In K. Csizér \& M. Magid (Eds.), The impact of self-concept on language learning (pp. 250-266). Bristol, UK: Multilingual Matters.

Yue, Z. 2016. Exploring Chinese university EFL learners' L2 willingness to communicate in action: Understanding the interplay of self-concept, WTC and sociocultural context through the lens of complexity theory ( $\mathrm{PhD}$ thesis). University of Birmingham, Birmingham, UK.

Zhao, Z. (2012). EFL Teaching and reform in China's tertiary education. Journal of Language Teaching and Research, 3(6), 1098-1104. doi:10.4304/jltr.3.6.1098-1104

Zimmerman, D. H. (1998). Discoursal identities and social identities. In C. Antaki \& S. Widdicombe (Eds.), Identities in talk (pp. 87-106). London, UK: Sage.

Zhou, N. (2015). Oral participation in EFL classroom: Perspectives from the administrator, teachers, and learners at a Chinese university. System, 53, 35-46.

doi:10.1016/j.system.2015.06.007 


\section{Appendices}

Appendix A

Transcription Conventions

(.) slight pause

(4) pause in seconds

$=$ latched speech

\{overlapping speech\}

/translation/

((field notes))

S: unidentified individual student

SS: unidentified students simultaneously 